\title{
PURE CHITOSAN MICROFIBRES FOR BIOMEDICAL APPLICATIONS
}

\author{
Georgios Toskas, Ronny Brünler, Heike Hund, Rolf-Dieter Hund, Martin Hild, Dilibaier Aibibu, Chokri Cherif
}

\author{
Institute of Textile Machinery and High Performance Material Technology (ITM) at TU Dresden \\ Hohe Straße 6, 01069 Dresden, Germany \\ e-mail: georg.toskas@gmx.de; gtoskas@gmail.com
}

\begin{abstract}
:
Due to its excellent biocompatibility, Chitosan is a very promising material for degradable products in biomedical applications. The development of pure chitosan microfibre yarn with defined size and directional alignment has always remained a critical research objective. Only fibres of consistent quality can be manufactured into textile structures, such as nonwovens and knitted or woven fabrics. In an adapted, industrial scale wet spinning process, chitosan fibres can now be manufactured at the Institute of Textile Machinery and High Performance Material Technology at TU Dresden (ITM). The dissolving system, coagulation bath, washing bath and heating/drying were optimised in order to obtain pure chitosan fibres that possess an adequate tenacity. A high polymer concentration of $8.0-8.5 \% \mathrm{wt}$. is realised by regulating the dope-container temperature. The mechanical tests show that the fibres present very high average tensile force up to $34.3 \mathrm{~N}$, tenacity up to $24.9 \mathrm{cN} / \mathrm{tex}$ and Young's modulus up to $20.6 \mathrm{GPa}$, values much stronger than that of the most reported chitosan fibres. The fibres were processed into $3 D$ nonwoven structures and stable knitted and woven textile fabrics. The mechanical properties of the fibres and fabrics enable its usage as textile scaffolds in regenerative medicine. Due to the osteoconductive properties of chitosan, promising fields of application include cartilage and bone tissue engineering.
\end{abstract}

\section{Keywords:}

Chitosan, Industrial scale wet spinning, High tenacity chitosan fibre, Nonwoven scaffold, Knitted/woven chitosan fabric, Regenerative medicine

\section{Introduction}

Among the different classes of polymers, biodegradable biopolymers, obtained from natural wastes, are of increasing importance for their application in several domains. Chitosan (CTS), a natural cationic polymer, possesses unique properties: it is biologically renewable, biodegradable, biocompatible, non-antigenic, non-toxic and biofunctional. This modified biopolymer is manufactured from natural marine waste. Chitin from crustacean shells (e.g. from crabs and shrimps) is the second most abundant natural polymer in the world and presents an analogue of cellulose with $\mathrm{N}$-acetyl groups instead of hydroxyl groups in position 2. Chitin is converted to CTS by alkaline treatment. Alkali splits most of $\mathrm{N}$-acetyl groups $(75 \%$ $95 \%)$ generating free amino groups that provide fungistatic and bacterostatic effects [1]. CTS, a high molecular weight polysaccharide composed of $\beta$-(1,4)-2-acetamido-2-deoxy$D$-glucose and $\beta$ - $(1,4)-2$-amino-2-deoxy-D-glucose units, is therefore a deacetylated form of chitin. It has immense structural possibilities for chemical and mechanical modifications which can generate novel properties, functions and applications especially in the biomedical field.

There have been several attempts of CTS fibre fabrication by applying the wet spinning method. The development of fibres from CTS was possible as it is soluble in dilute acids such as acetic acid. Thus, CTS fibres of various tensile/mechanical properties could be made with a variety of spinning conditions. It was also postulated that the fibre properties are affected by the production conditions rather than by their chemical nature
[2]. The non-Newtonian shear thinning behaviour of the solutions at higher concentrations poses a major challenge. A dramatic increase in solution viscosity occurs at higher CTS concentrations, with the $5.86 \%$ solution showing a viscosity of more than 500 poises. A maximum of $5 \%-6.5 \%$ CTS solution was, therefore, used as the spinning dope in all previous CTS spinning trials [2-4]. Various methods, such as the use of inorganic salts and the polyelectrolyte screening effect $[5,6]$, were used for lowering the solution viscosity. The drying conditions also had a big effect on the fibre properties. The fibre obtained by air drying had a much higher extensibility than those dried by radiant heating. In general, fibre tenacities of about $20 \mathrm{cN} /$ tex were obtained with an elongation at break of $8.0 \%$ in yarns up to 8 tex [2]. Higher fibre strengths have been reported by using special spinning conditions such as the dry-jet-stretching gel-spinning technique [7] or an ionic liquid as a spinning dope solution solvent $[8,9]$. Another laboratory approach employed $\mathrm{LiOH} /$ urea as solvent system and two coagulant baths for fibre stabilisation [10]. The use of ionic liquids as green solvents, such as CTS-[Gly]Cl (glycine chloride) [8], or the binary ionic liquid system composed of glycine hydrochloride $(\mathrm{Gly} \cdot \mathrm{HCl})$ and $[\mathrm{Bmim}] \mathrm{Cl}$ starting from $\mathrm{N}$-methylimidazole and 1-chlorobutane [9], led to higher strength CTS fibres. Nevertheless, these methods involve delicate synthesis of ionic liquids, which make the industrial scale fibre production a complex process.

The development of new absorbable materials, e.g. for bone or cartilage replacement, remains an important aim in regenerative medicine. Recently, the use of $3 D$ woven 
fabric scaffolds has gained importance for their application in cartilage regeneration [11]. CTS scaffolds are osteoconductive and can enhance bone formation both in vitro and in vivo $[12,13]$. But, in spite of its general acceptance as a tissue biocompatible material, CTS itself in the form of porous sponges, membranes and non-woven fabrics is mechanically rather weak and unstable, and unable to maintain a predefined shape for transplantation as a result of swelling (poor bedding behaviour) [14]. Thus, a critical research objective is the fabrication of well-defined CTS macrofibres and microfibres and threads of concrete size and directional alignment, which could lead to textile structure, e.g. nonwoven, woven and/or knitted fabrics. The construction of such fabrics has not been possible yet with pure CTS fibres.

\section{Experimental part}

\section{Materials}

CTS of various grades, degree of deacetylation (DA), viscosity and molecular weight were purchased from Heppe Medical Chitosan $\mathrm{GmbH}$, Germany. For example, CTS (95/500) is a CTS grade with a DA degree of $95 \%$, viscosity of $500 \mathrm{mPas}$ ( $1 \%$ wt. CTS in $1 \%$ wt. acetic acid) and $\mathrm{Mw}=350 \mathrm{KDa}$. Other grades used were as indicative: CTS (95/50), (90/50), (95/100) $(80 / 100)$ with $\mathrm{Mw}=300 \mathrm{KDa},(85 / 100)$ with $\mathrm{Mw}=310 \mathrm{KDa}$. Glacial acetic acid $(\mathrm{AcOH})$ and other reagents were purchased from MERCK, Germany.

\section{Preparation of spinning dope solution}

Using up to $8.5 \%$ wt. of CTS, the viscosity of the spin dope was optimised by an acetic acid buffer solution, giving a $\mathrm{pH}$ of 4.5 , and through appropriate temperature elevation. In a range of $3.7-5.6 \mathrm{pH}$, aggregation is prevented [15,16]. The solution was filtered through a candle filter system and stirred for 5-10 hours. Subsequently it was degassed under vacuum.

\section{Rheology}

A Haake MARS II (Thermo Scientific, USA) stress-controlled rheometer was used for the measurements of the solutions viscosity parameters. Cone-plate geometry $(35 \mathrm{~mm}$ diameter, $2^{\circ}, \mathrm{Ti}$ ) was used for the shear measurements and the oscillatory movement. The gap was $0.100 \mathrm{~mm}$ for all solutions at a temperature of $20 \pm 0.1^{\circ} \mathrm{C}$.

\section{Infrared spectroscopy}

IR spectra were obtained by using the Attenuated Total Reflection method on a Nicolet 6700 (Thermo Scientific, USA) FTIR spectrometer. A total of 64 scans were taken and averaged from 650 to $4000 \mathrm{~cm}^{-1}$ with a resolution of $4 \mathrm{~cm}^{-1}$ for each spectrum.

\section{Thermal analysis}

Thermal Gravimetric Analysis (TGA) was carried out on a TGA Q500 (TA Instruments, USA) under high-purity nitrogen with a flow rate of $50 \mathrm{~mL} / \mathrm{min}$. The heating rate was varied up to $40 \mathrm{~K} / \mathrm{min}$, depending on actual decomposition rate (Hi-Res technique).

\section{Tensile tests}

Tensile properties of the CTS yarn samples were measured according to DIN EN ISO 2062 on a Z2.5 tensile tester (Zwick, Germany) with a $100 \mathrm{~N}$ load sensor. The gauge length was $250 \mathrm{~mm}$ and the extension rate was $250 \mathrm{~mm} / \mathrm{min}$. For the tensile test of the fabric, the DIN EN ISO 13934-1 was applied with a ZMART.PRO $10 \mathrm{kN}$ sensor on a UPM 1445 tensile tester (Zwick, Germany). The tests were performed at $20^{\circ} \mathrm{C}, 65 \%$ R.H. The tensile tests were carried out on 10 samples of each fibre quality, the standard deviation being generally less than $5 \%$.

\section{Results and discussion}

\section{Wet spinning of CTS fibres}

Several physical, chemical and mechanical problems concerning the fibre construction had to be addressed and solved. The solution viscosities, spin stretch ratio (ratio of take-up speed to extrusion rate) adjustment, coagulation bath regulation and drying methods are some of the parameters that had to be examined and regulated. The various chemical and spinning parameters were optimised in order to fabricate CTS fibres with adequate tenacity and elastic modulus capable of producing knitted and/or woven fabric without the need of blending or reinforcing. A specially constructed, industrial scale, wet spinning machine from Fourné Polymertechnik $\mathrm{GmbH}$, Germany, is used for the wet spinning of the CTS fibres (Figure 1). Consequently, all the physical-mechanical parameters are set up and monitored by a fully computerised system (Figure 1, upper right panels).

The preparation of the spinning dopes is described in the experimental section. A typical spinning dope is prepared by dissolving about $2.7 \mathrm{~kg}$ CTS with a DA of $95 \%$ in $34 \mathrm{~L}$ of aqueous acetic acid solution giving a CTS concentration of $8.0 \%-8.5 \%$ wt. The CTS solution is transferred to the wet spinning machine container of $100 \mathrm{~L}$ and stirred overnight. Processing high concentrations of CTS requires knowledge of the rheology of the spinning solutions. Figure $2 a$ shows the shear viscosity $\left(\eta_{\text {dyn }}\right)$ as a function of the shear rate. Figure $2 b$ shows the influence of the temperature on the shear viscosities at a constant shear rate. At room temperature it is measured as $87 \mathrm{~Pa} \cdot \mathrm{s}$ while at $60^{\circ} \mathrm{C}$ it is measured as $55 \mathrm{~Pa} \cdot \mathrm{s}$, approximately $36 \%$ smaller. This allows lowering the CTS solution's viscosity by regulating temperature in the machine's dope-tank and constitutes a clear advantage for the successful spinning through the nozzles. After stirring, the solution is heated up to $60^{\circ} \mathrm{C}$ and ejected through a jet nozzle having $150-600$ holes of $20-120 \mu \mathrm{m}$.

The coagulation bath is composed of $0.5 \mathrm{M} \mathrm{NaOH} / 10 \% \mathrm{EtOH}$ and is heated up to $30-45^{\circ} \mathrm{C}$ (Figure 3). The as-spun fibres are washed in a $30-50^{\circ} \mathrm{C}$ water bath and in three other baths 


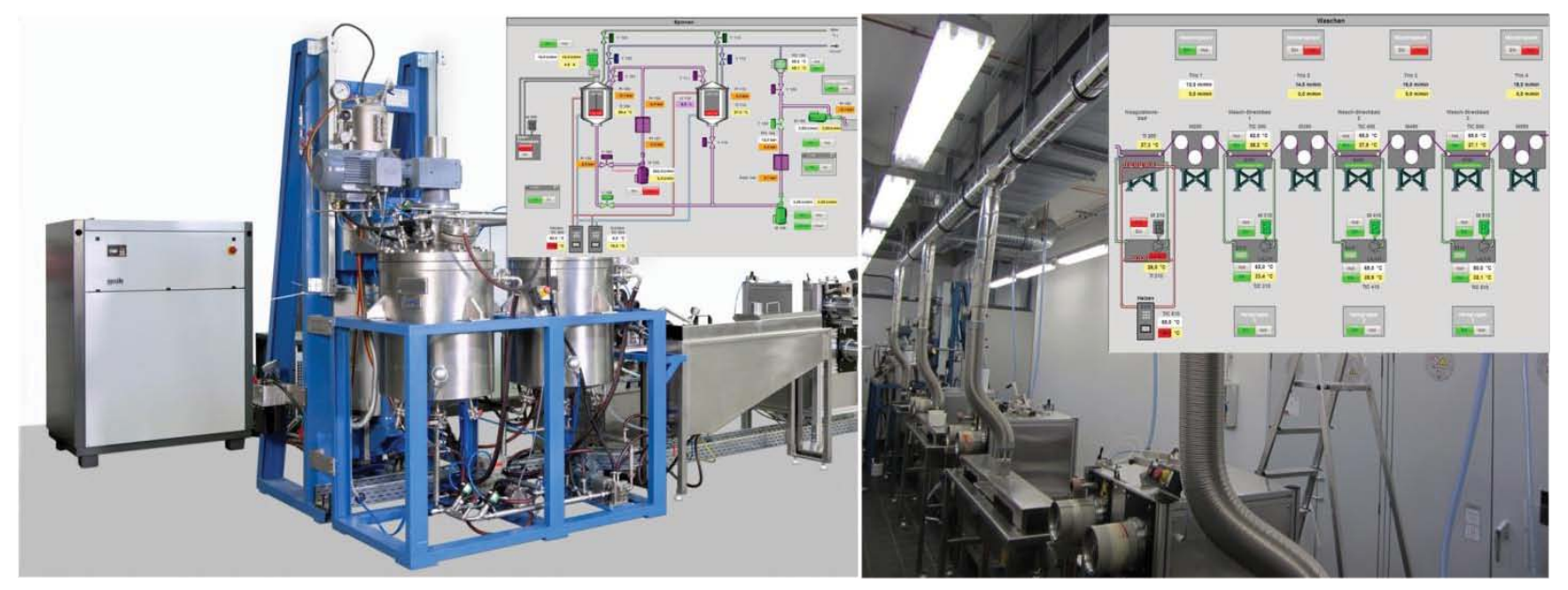

Figure 1. The ITM fully computerised industrial wet spinning machine.

a

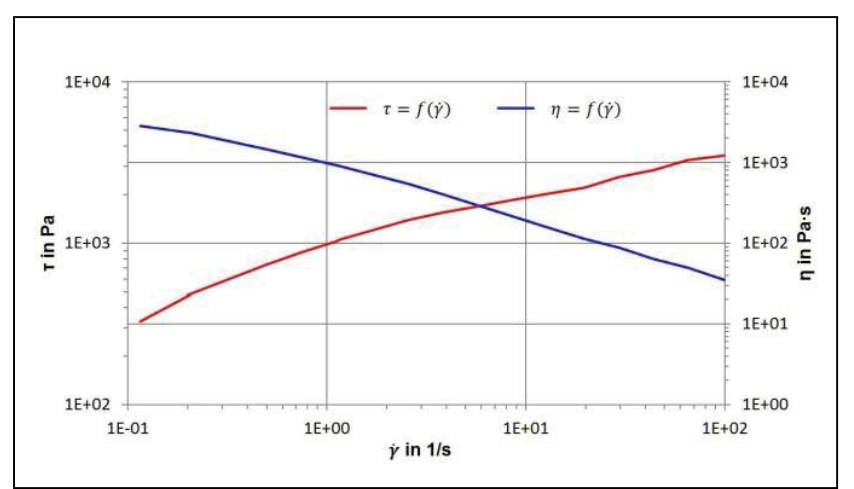

b

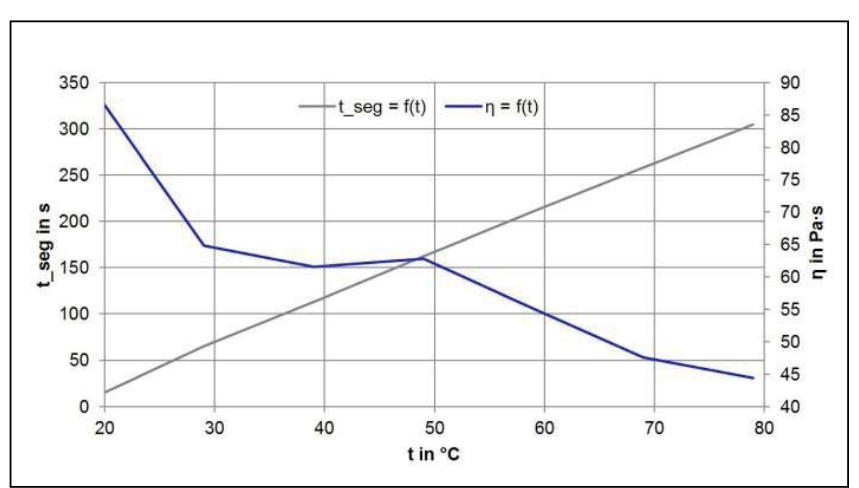

Figure 2. Shear viscosity (right y-axis) as a function of shear rate of a chitosan $8.0 \%$ wt. solution (a) and shear viscosity evolution upon temperature raising from $20^{\circ}$ to $80^{\circ} \mathrm{C} s$ at $y=10 \mathrm{~s}^{-1}$.
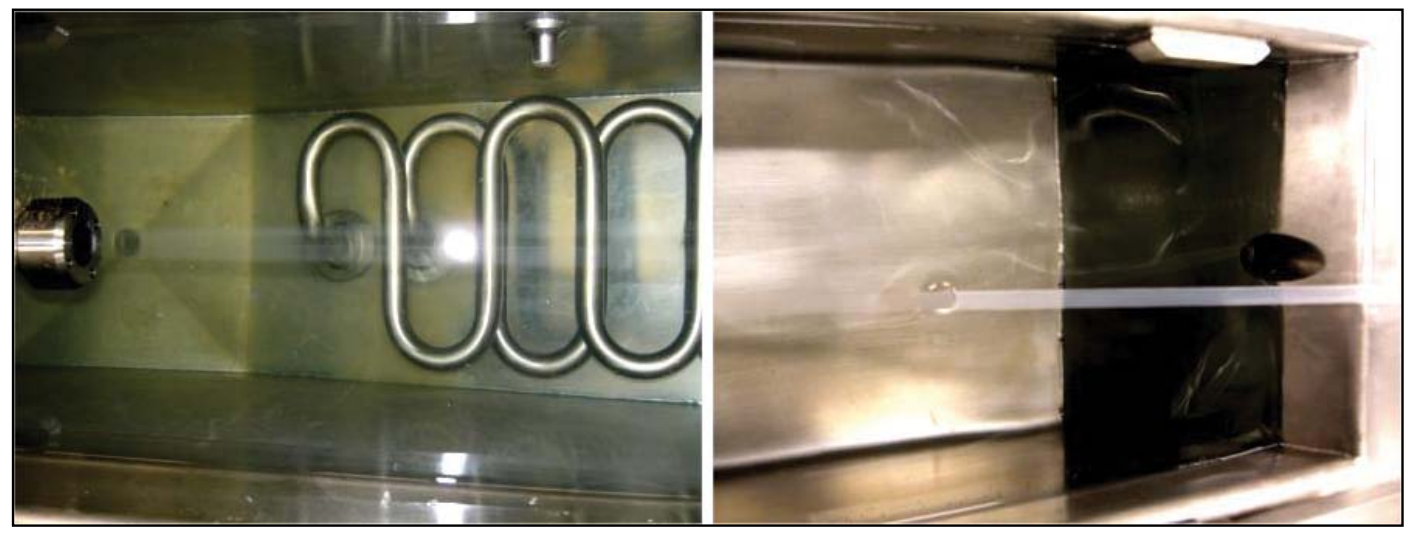

Figure 3. Wet spinning of pure chitosan through the coagulation bath.

at an ambient temperature $\left(20^{\circ} \mathrm{C}\right)$. Then, the fibres pass the air-drying units four times to be subsequently dried at elevated temperature and finally are wound up to $2-3 \mathrm{Kg}$ bobbins. The optimum draw ratio is settled 1.20 to 1.30 at a take-up speed up to $25 \mathrm{~m} / \mathrm{min}$.

\section{CTS fibre/fabric morphology and mechanical properties}

CTS microfibres with average fibre diameters of 20-36 $\mu \mathrm{m}$ were produced from CTS dopes dissolved in acidic solutions.
The fibres show uniform and smooth surfaces with dense structured cross sections (Figure 4).

The tested yarns have up to 300 filaments resulting in yarn counts ranging from 30 to 350 tex. They possess tenacities from 9.9 to $24.9 \mathrm{cN} / \mathrm{tex}$, Young's modulus of 7.0 to $20.6 \mathrm{GPa}$ and $1.9 \%$ to $5.7 \%$ elongation at break (Table 1 ).

The fibres' Young's modulus meets that of the human cortical bone [17]. The mechanical properties also make further textile 
a

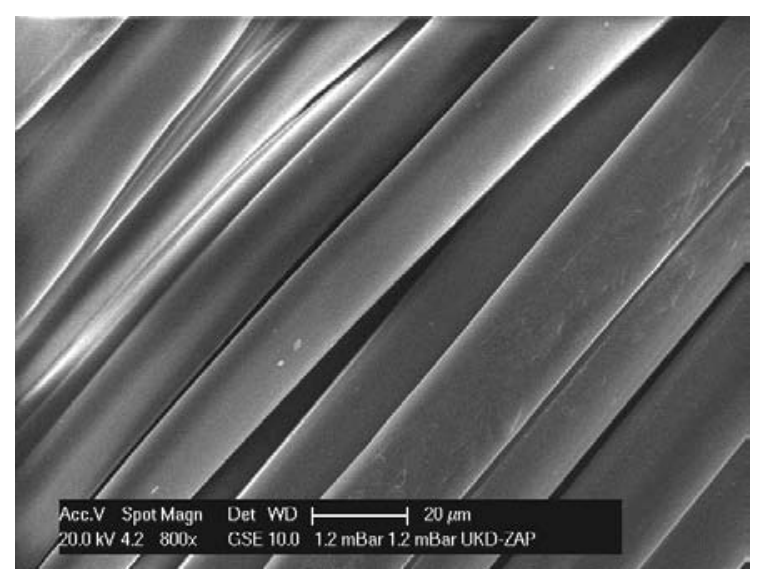

b

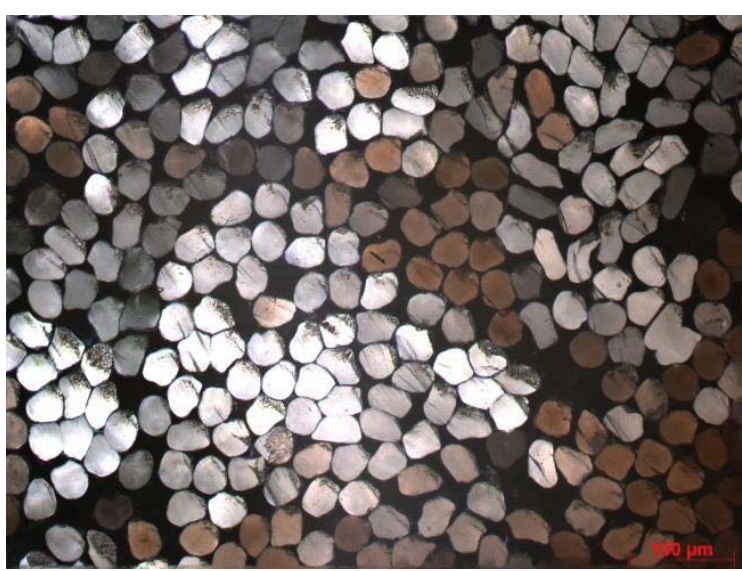

Figure 4. Chitosan TS fibres (a) and their cross section (b).

Table 1. Mechanical properties of selected chitosan fibres.

\begin{tabular}{|c|c|c|c|c|c|c|}
\hline $\begin{array}{c}\text { Deacetylation [\%]/Yarn } \\
\text { count }\end{array}$ & $\begin{array}{c}\text { Spin nozzle/ } \\
\text { holes }\end{array}$ & $\begin{array}{c}\text { Diameter } \\
{[\boldsymbol{\mu} \mathbf{m}]}\end{array}$ & $\begin{array}{c}\text { Tensile } \\
\text { Force [N] }\end{array}$ & $\begin{array}{c}\text { Tenacity } \\
{\left[\mathbf{c N} \cdot \mathbf{t e x}^{-1} \text { ] }\right.}\end{array}$ & $\begin{array}{c}\text { Elongation at } \\
\text { break [\%] }\end{array}$ & $\begin{array}{c}\text { Young's } \\
\text { modulus [GPa] }\end{array}$ \\
\hline $90 / 317$ tex & $120 \mu \mathrm{m} / 210$ holes & 36.0 & 34.3 & 10.8 & 5.7 & 10.0 \\
\hline $90 / 146$ tex & $120 \mu \mathrm{m} / 210$ holes & 25.0 & 23.3 & 15.9 & 2.2 & 20.6 \\
\hline $95 / 169$ tex & $90 \mu \mathrm{m} / 300$ holes & 20.7 & 16.9 & 10.0 & 3.0 & 12.3 \\
\hline
\end{tabular}

processing possible. The increased value of fibre tenacity is related to an increase in orientation and alignment of the fibres, while the elastic modulus is connected with the crystalline domains. Therefore, it is assumed that better orientation of the amorphous areas leads to fibres of very high tenacity. A typical stress/strain curve is shown in Figure 5.

Examination of the mechanical properties of fibres fabricated from the same CTS raw material and extracted by the same spin nozzles shows the construction of uniformly distributed monofilaments in cross sections. By raising the yarn count, the diameters and tensile force are normally increasing. This is not the case for the Young's modulus, where in the case of smaller yarn count it is found to increase. This could again be attributed to the growth of crystalline domains in optimally drawn fibres after spinning.

\section{Thermal and structural fibre analysis}

The TGA curves of the raw CTS powder (DA 95\%) and that of the corresponding constructed fibres are shown in Figure 6. After an initial weight loss of about $10 \%$ wt. at around $100^{\circ} \mathrm{C}$ coming from the moisture content, the fibres show an increased starting (onset) decomposition temperature of $\mathrm{T}_{\text {onset }}=287^{\circ} \mathrm{C}$ compared with the raw material $\left(T_{\text {onset }}=273^{\circ} \mathrm{C}\right)$. The maximum rate of decomposition also occurs in higher temperature, $T_{\text {end }}=$ $310^{\circ} \mathrm{C}$. This shows a better thermal stability of the fibres which can be related to strong inter- and intra-molecular hydrogen bond interactions and good crystallinity. This is also supported by the delay in weight loss of the fibres decomposition (48.9\% wt.) after $300^{\circ} \mathrm{C}$ (Figure 6), compared with the raw CTS powder presenting a sharper final decomposition (56.8\% wt.)

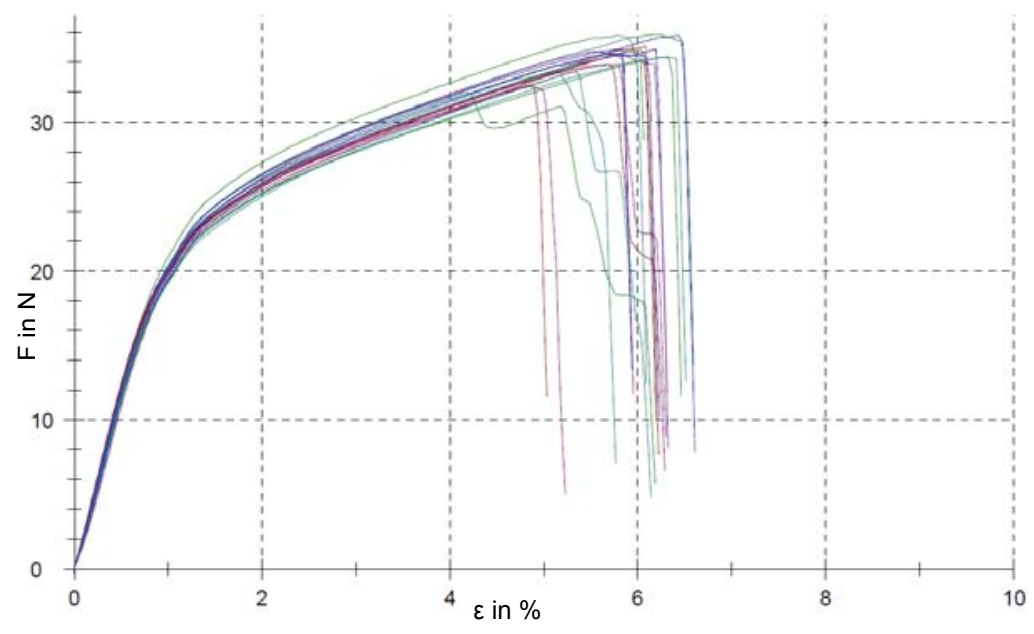

Figure 5. Typical stress/strain curve of fabricated chitosan fibre (See Table 1/line 1). 
(Table 2). What is also remarkable in the raw-materials and fibres is the very small residual ratio measured in many cases as $0 \%$ wt. This is far smaller than that reported recently by $\mathrm{Ma}$ et al. accounting to $38 \%$ wt. [9]. The residual ash reported in Table 2 is the maximum amount measured, which stands for the fibres at $0.59 \%$ wt. This shows that the fibres are ultra-pure, containing no impurities.

Table 2. Thermal analysis of the raw $95 \%$ deacetylation chitosan (CTS) powder and fabricated CTS fibres

\begin{tabular}{|c|c|c|}
\hline Sample & Raw CTS powder & Fibre \\
\hline $\mathrm{T}_{\text {onset }}\left({ }^{\circ} \mathrm{C}\right)$ & 273 & 287 \\
\hline $\mathrm{T}_{\text {end }}\left({ }^{\circ} \mathrm{C}\right)$ & 289 & 310 \\
\hline Weight loss after $300^{\circ} \mathrm{C}$ & $56.8 \%$ & $48.9 \%$ \\
\hline Residual ratio \% wt. & $0.57 \%$ & $0.59 \%$ \\
\hline
\end{tabular}

The FT-IR spectra of the CTS raw powder (DA 95) and the corresponding fibre prepared by this material are virtually identical (Figure 7). The absorption peaks observed at 1653 and $1587 \mathrm{~cm}^{-1}$ are assigned to the carbonyl, $\mathrm{C}=\mathrm{O}-\mathrm{NHR}$ absorption band and the amine $-\mathrm{NH}_{2}$, respectively. These are characteristic of CTS and are denoted as amide I and II, respectively [18]. The wide peak at $3362 \mathrm{~cm}^{-1}$ is assigned to the stretching of the CTS hydroxyl groups. The medium band at $2878 \mathrm{~cm}^{-1}$ and the strong triplet band at $1152 \mathrm{~cm}^{-1}, 1074 \mathrm{~cm}^{-1}$ and $1034 \mathrm{~cm}^{-1}$ with a maximum at $1074 \mathrm{~cm}^{-1}$ are attributed to the $\mathrm{C}-\mathrm{H}$ stretch and $\mathrm{C}-\mathrm{O}-\mathrm{C}$ accordingly. The identical bands observed by the raw material and the fibres show that the $-\mathrm{NH}_{3}{ }^{+}$groups in the CTS backbone are deprotonated by the alkali treatment occurring in the neutralisation bath. Finally, the chemical structure of CTS is maintained within the fibres.

The micro fibrous filament yarns were cut into short fibres with a length of $0.5-2 \mathrm{~mm}$ in order to produce nonwoven structures as scaffolds using the patented Net-Shape-Nonwoven technique

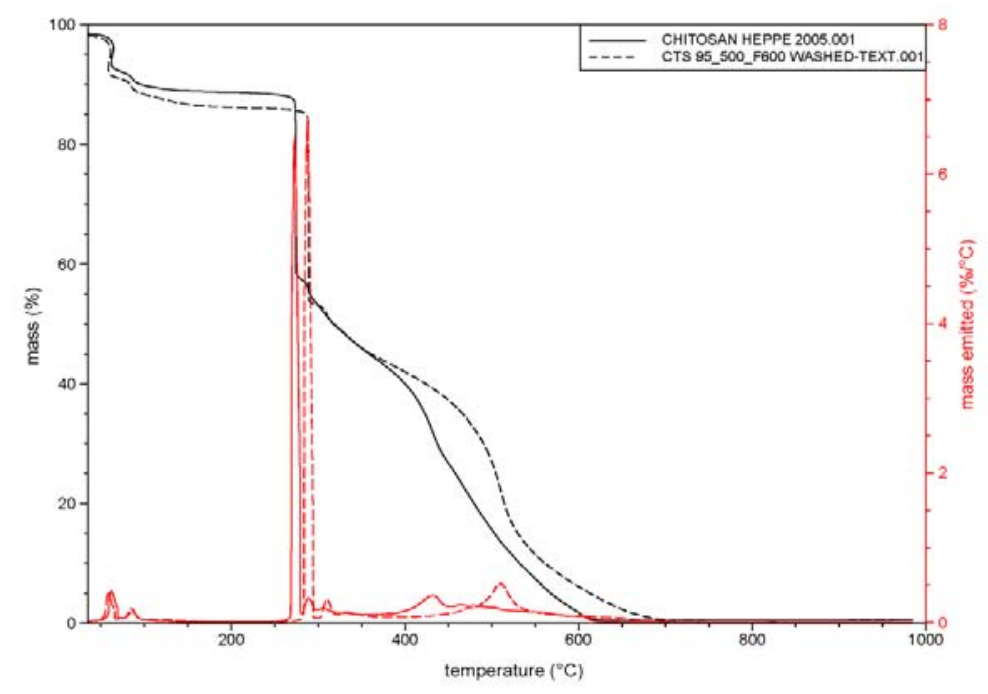

Figure 6 Thermal analysis curves of the raw chitosan (CTS) powder (continuous line) and fabricated CTS fibres (dotted line).

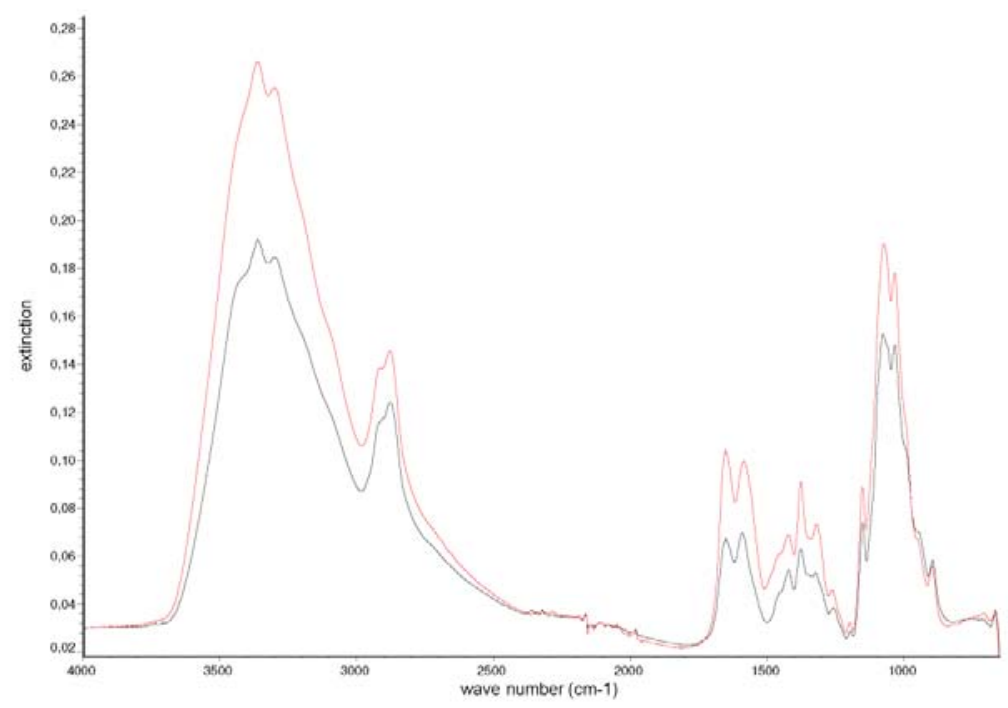

Figure 7. FT-IR spectra of the chitosan (CTS) fibre (red line) and the raw CTS powder (black line). 


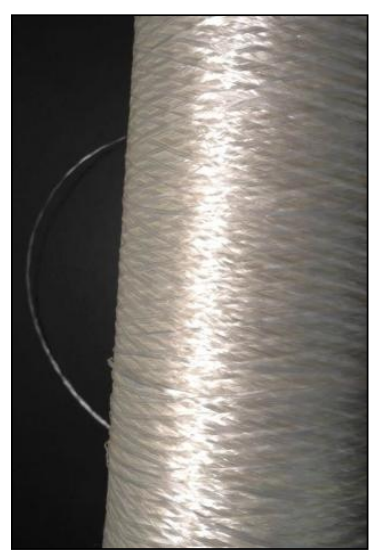

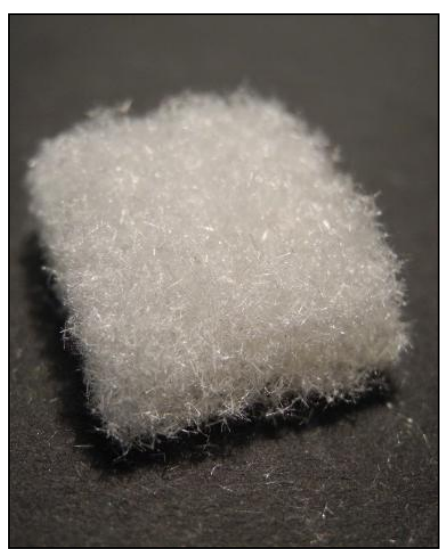

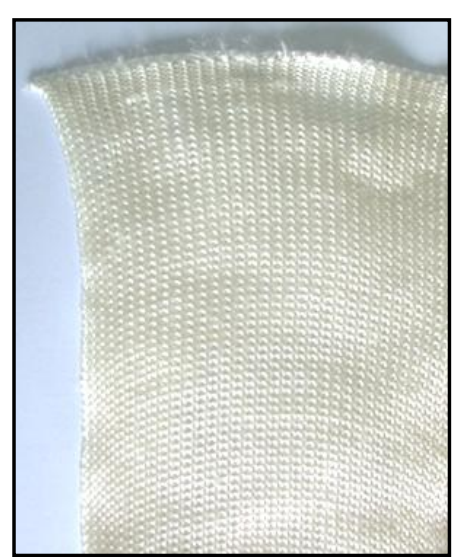

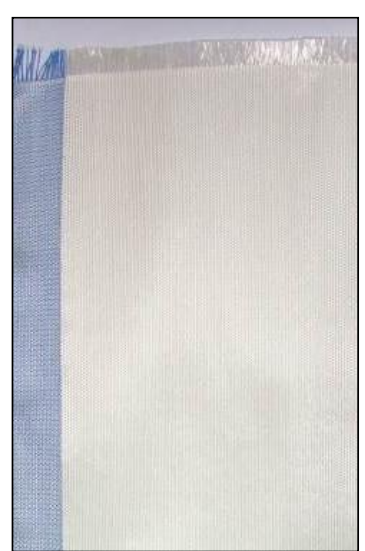

Figure 8. Pure chitosan bobbin (a), nonwoven (b), knitted (c) and woven (d) textile fabric.

(Figure 8a,b) [19]. Furthermore, the fibres were subsequently knitted or woven giving a stable textile fabric (Figure 8c,d). Tensile force of both knitted and woven fabric is shown in Table 3. A further possibility of obtaining CTS based scaffolds is using electrospinning of CTS derivates [20].

Table 3. Mechanical properties of chitosan (CTS) knitted and woven fabric

\begin{tabular}{|l|c|c|}
\hline & Tensile force & Elongation at break \\
\hline CTS knitted fabric & $242 \mathrm{~N}$ & $9.6 \%$ \\
\hline CTS woven fabric & $245 \mathrm{~N}$ & $11.4 \%$ \\
\hline
\end{tabular}

\section{Conclusions}

Ultra-pure CTS fibres were fabricated in an industrial scale by wet spinning. A high concentration up to $8.5 \%$ wt. of CTS was possible through adequate heating and stirring of spinning dopes. The whole process was optimised in physico-chemical terms and fully monitored by a computerised system. Attention has been given to the industrial feasibility and reproducibility of the method. Fibres with adjustable diameters and tenacities up to $24.9 \mathrm{cN} /$ Tex could be obtained, allowing further processing into knitted or woven fabrics and nonwovens. The strong mechanical properties of the pure CTS fibres and fabrics constructed reveal their potential ability to be used as textile scaffolds in regenerative medicine and more specifically in cartilage/bone tissue engineering. Future research steps include the sterilisation of the constructed fabrics and testing their suitability for different tissue types in cell cultures. The mechanical stability of the developed CTS fibres allows the construction of more stable nonwoven scaffolds and other structures for regenerative medicine.

\section{Acknowledgement}

This research project (DFG CH 174-24/1) is financed by "Deutsche Forschungsgemeinschaft".

\section{References}

[1] Muzzarelli, R. A. A., Muzzarelli, C.: Chitosan chemistry: relevance to the biomedical sciences, Advanced Polymer Science, Vol. 186, p. 151-209, 2005.

[2] East, G. C. and Qin, Y.: Wet spinning of chitosan and the acetylation of chitosan fibers, Journal of Applied Polymer Science, Vol. 50, p. 1773-1779, 1993.

[3] Agboh, O.C. and Qin, Y.: Chitin and chitosan fibres. Polymer Advanced Technology, Vol. 8, p. 355-365, 1997.

[4] Hirano, S., Zhang, M., Chung, B. G., Kim S. K.: The $\mathrm{N}$-acylation of chitosan fibre and the $\mathrm{N}$-deacetylation of chitin fibre and chitin-cellulose blended fibre at a solid state, Carbohydrate Polymers, Vol. 41, p. 175-179, 2000.

[5] El-Tahlawy, K., Hudson, S. M.: Chitosan: Aspects of fiber spinnability, Journal of Applied Polymer Science, Vol. 100, No 2, p. 1162-1168, 2006.

[6] Pillai, C.K.S., Paul, W., Sharma, C. P.: Chitin and chitosan polymers: Chemistry, solubility and fiber formation, Progress in Polymer Science, Vol. 34, No 7, p. 641-678, 2009.

[7] Notin, L., Viton, C., David, L., Alcouffe, P., Rochas, P., Domard, A.: Morphology and mechanical properties of chitosan fibers obtained by gel-spinning: Influence of the dry-jet-stretching step and ageing, Acta Biomaterialia, Vol. 2, p. 387-402, 2006.

[8] Li, L., Yuan, B., Liu, S., Yu, S., Xie, C., Liu, F., Guo, X., Pei, L., Zhang, B.: Preparation of High force Chitosan Fibers by Using lonic Liquid as Spinning Solution, Journal of Materials Chemistry, Vol. 22, p. 8585-8593, 2012.

[9] Ma, B., Qin, A., Li, X., He, Ch.: High tenacity regenerated chitosan fibers prepared by using the binary ionic liquid solvent (Gly.HCl)-[Bmim]Cl, Carbohydrate Polymers, Vol.97, p. 300-305, 2013.

[10] Li, Y., Zhuang, P., Zhang, Y., Wang, Z., Hu, Q.: A new approach for preparing chitosan fibers from a LiOH/urea solvent system, Materials Letters, Vol.84, p. 73-76, 2012.

[11] Moutos, F. T., Freed, L. E. and Guilak F.: A biomimetic three-dimensional woven composite scaffold for functional tissue engineering of cartilage, nature materials, Vol. 6, $p$. 162-167, 2007.

[12] Tuzlakoglu, K., Alves, C. M., Mano, J. F., Reis R. L.: Production and Characterization of Chitosan Fibers 
and 3-D Fiber Mesh Scaffolds for Tissue Engineering Applications, Macromolecular Bioscience, Vol. 4, p. 811819, 2004.

[13] Heinemann, C., Heinemann, S., Lode, A., Bernhardt, A., Worch, H., Hanke T.: In Vitro Evaluation of Textile Chitosan Scaffolds for Tissue Engineering using Human Bone Marrow Stromal Cells, Biomacromolecules, Vol. 10, p. 1305-1310, 2009.

[14] Bhattarai, N., Edmondson, D., Veiseh, O., Matsen, F. A., Zhang M.: Electrospun chitosan-based nanofibers and their cellular compatibility, Biomaterials, Vol. 26, p. 61766184, 2005.

[15] Rinaudo, M., Pavlov, G., Desbrières, J.: Influence of acetic acid concentration on the solubilization of chitosan, Polymer, Vol. 40, p. 7029-7032, 1999.

[16] Hamdine, M., Heuzey, M.-C., Bégin, A.: Effect of organic and inorganic acids on concentrated chitosan solutions and gels, International Journal of Biological Macromolecules, Vol. 37, p. 134-142, 2005.
[17]Rho, J.Y.: Young's modulus of trabecular and cortical bone material: ultrasonic and microtensile measurements, Journal of Biomechanics, Vol. 26, No, $p$. 111-119, 1993.

[18] Shirosaki, Y., Tsuru, K., Satoshi Hayakawa, S., Osaka, A., Lopes, M. A., Santos, J. D. et al.: Physical, chemical and in vitro biological profile of chitosan hybrid membrane as a function of organosiloxane concentration, Acta Biomaterialia, Vol. 5, p.346-355, 2009.

[19] Hild, M.; Jäger, M.; Aibibu, D.; Cherif, Ch.; Hanke, Th.: Three dimensional net-shape-nonwoven chitosan scaffolds for bone tissue engineering applications. In: CD-Rom. 13th World Textile Conference AUTEX 2013, Dresden, 22.-24. Mai 2013

[20] Cheng, T.; Hund, R.; Cherif, C.; Aibibu, D.; Horakova, M.: Chitosan and Chitosan Derivative Nanofibers Made by Single Step Electrospinning, Autex Research Journal, Volume 13 (Accepted) 